\title{
Sorption of Zinc (II) and Copper (II) Ions from Synthetic Wastewater by Yam (Dioscorea Rotundata) Peel Waste Biosorbent
}

\author{
Akhigbe L.O. ${ }^{1}$, Omoregie, D.O. ${ }^{1}$ and Ehiorobo, J.O. ${ }^{1, *}$ \\ ${ }^{1}$ Department of Civil Engineering, University of Benin, Benin City, Nigeria \\ Corresponding Author:*jacehi@uniben.edu
}

\begin{abstract}
There is a growing concern about the potential health hazard posed by heavy metals in the environment. The removal of metals from individual wastewater has become of primary importance because contamination of wastewater by heavy metals is a very serious environmental and health problem. Some of the existing methods of wastewater treatment are beyond the abilities of many local industries. Of recent, the use of non-living biomaterials as metal-binding compounds has been gaining advantage because the high levels of contamination do not affect them. Moreover, they require minimum care and maintenance and can be obtained cheaply. In this study acid-activated yam peel waste biosorbent was used for the removal of $\mathrm{Zn}$ (II) and $\mathrm{Cu}$ (II) ions from synthetic wastewater under batch test conditions. The effects of initial concentration $(15-55 \mathrm{mg} / \mathrm{l})$ and contact time (20-100min) on removal performance were investigated with maximum removal efficiencies of $38 \%$ and $89 \%$ obtained for $\mathrm{Cu}$ (II) and Zn (II) respectively within 100 min. The Langmuir isotherm model provided a better fit for the equilibrium data obtained. Furthermore, adsorption of both metals was best described by the pseudo second order kinetic model based on the higher correlation coefficients and smaller error values obtained from statistical analysis. The findings of this study indicate the potential of this biosorbent for heavy metal removal applications.
\end{abstract}

Keywords: Yam Peels, Biosorbent, Synthetic Wastewater, Zinc, Copper, Adsorption

\subsection{Introduction}

Environmental pollution with heavy metals has become a global phenomenon as a consequence of industrial and metallurgical processes such as electroplating, petrochemical processing, manufacturing, tanning, etc., which introduce these toxic chemicals into the environment. These metals are nonbiodegradable, persistent in the environment and harmful to human health. Bioaccumulation and overexposure to metals such as lead, copper, zinc, cadmium and others may cause nausea, organ damage, death and increased risk of cancer (Sag and Kutsal, 1996; Sadeghi et al., 2006; Igwe and Abia, 2006; Aydin et al., 2008).

Several techniques are applied in the removal of heavy metals from industrial effluents. These include chemical precipitation, ion exchange, electrodialysis, membrane separation and adsorption. However high treatment costs and large quantities of sludge generated are major limitations of some of these methods (Bailey et al., 1999; Blanco et al., 1999). Biomaterials such as agricultural wastes have been employed as alternatives for metal removal due to their availability and low cost. Several studies have shown that non- living plant biomass materials are effective for the removal of trace metals from the environment (Mofa, 1995; Alderhold et al., 1996; Gardea et al., 1996; Okuo and Ozioka, 2001; Okuo et al., 2006; Rao et al., 2008; Raghavaro et al., 2009). The unique ability of these materials to bind metals has been attributed to the presence of various functional groups that can attract and sequester metal ions (Gardea et al., 1990). Cellulosic non- reducing carbohydrate polysaccharides found in plant fibre such as yam peels can be used as cheap materials with the potential of removing metals from their solutions (Owamah et al., 2013). Conversion of these low-value yam wastes into biosorbent for the removal of toxic metals from industrial wastewater would increase their market value. 
Hence, the aim of this study was to investigate the use of yam (Dioscorea Rotundata) peels converted into biosorbent for the removal of heavy metal ions (Cu (II) and $\mathrm{Zn}$ (II)) from synthetic wastewater. The adsorption isotherms and kinetics were also determined.

\subsection{Materials and Methods}

\subsection{Preparation of Acid-Activated Yam Peel Biosorbent}

White yam (Dioscorea Rotundata) tubers were washed with deionized water, air-dried and peeled. The yam peels were air-dried for $24 \mathrm{hrs}$ and later oven dried at $90^{\circ} \mathrm{C}$ to constant weight. The dried samples were ground, sieved to obtain a particle size of $75 \mu \mathrm{m}$ and stored in a desiccator. $400 \mathrm{~g}$ of yam peels was soaked in $0.3 \mathrm{M} \mathrm{HNO}_{3}$ for $24 \mathrm{~h}$ and washed with deionized water until a $\mathrm{pH}$ of 7.1 was obtained. The solution was filtered using Whatman filter paper 1 and the peels were air-dried. Acid treatment was undertaken by mixing $50 \mathrm{~g}$ of yam peels with $250 \mathrm{ml}$ of $1 \mathrm{M}$ concentration of $\mathrm{H}_{3} \mathrm{PO}_{4}$ acid (Phosphoric acid) for $6 \mathrm{~h}$ at $30^{\circ} \mathrm{C}$ while maintaining a $\mathrm{pH}$ of 7.1. The mixture was allowed to settle overnight and then centrifuged at $250 \mathrm{rpm}$ for $10 \mathrm{~min}$. The supernatant was discarded and the paste air-dried.

\subsection{Preparation of Synthetic Wastewater}

Stock solutions of the two metal ions were prepared by dissolving analytical grade copper(II) tetraoxosulphate (VI) $\left(\mathrm{CuSO}_{4}\right)$ and zinc (II) tetraoxosulphate (VI) ) $\mathrm{ZnSO}_{4}$ in deionized water respectively. The standard solutions $(15-55 \mathrm{mg} / \mathrm{l})$ were prepared by dilution of their respective stock solutions.

\subsection{Metal Removal Studies}

The biosorbent was mixed with $100 \mathrm{~mL}$ of $0.01 \mathrm{M}$ Hydrochloric acid (HCL) to obtain a slurry concentration of $2 \mathrm{mg} / \mathrm{mL}$. The effect of initial concentration on metal uptake was studied by agitating $2 \mathrm{~g}$ of wet biosorbent in $100 \mathrm{~mL}$ of metal ion solution $(15,25,35,45,55 \mathrm{mg} / \mathrm{l})$ at $\mathrm{pH}$ of 4.5 for $100 \mathrm{~min}$. The effect of contact time was studied by agitating $2 \mathrm{~g}$ of wet biosorbent in $100 \mathrm{~mL}$ of metal ion solution containing equal concentrations of $\mathrm{Cu}$ (II) and $\mathrm{Zn}$ (II) $(55 \mathrm{mg} / \mathrm{l})$ at $\mathrm{pH}$ of 4.5 for $20,40,60,80$ and 100 min. The metal concentrations of all treated solutions were determined using atomic absorption spectrometry (AAS) using a Buck Scientific Flame Atomic Absorption Spectrometer (FAAS) model $320 \mathrm{~N}$.

The metal ion uptake at equilibrium was determined using the equation expressed as (Badmus et al., 2007):

$$
q_{e}=\frac{v}{m}\left(C_{0}-C_{e}\right)
$$

Where $q_{e}$ is the amount of adsorbate adsorbed at equilibrium $(\mathrm{mg} / \mathrm{g}) ; C o$ and $C e$ are the initial and equilibrium metal ion concentrations respectively $(\mathrm{mg} / \mathrm{L}) ; v$ is the volume of solution $(\mathrm{mL})$ and $m$ is the mass of biosorbent $(\mathrm{g})$.

\subsection{Adsorption Isotherms}

The Langmuir and Freundlich adsorption isotherm models were used to analyse the adsorption equilibrium data obtained.

The Langmuir adsorption model is expressed as (Foo and Hameed, 2010):

$$
q_{e}=\frac{q_{\max } b C_{e}}{1+b C_{e}}
$$


Where $q_{e}$ and $q_{\max }$ are the amount of adsorbate adsorbed at equilibrium and the maximum monolayer coverage capacity respectively $(\mathrm{mg} / \mathrm{g}) ; C e$ is the equilibrium metal ion concentration $(\mathrm{mg} / \mathrm{L})$ and $b$ is the Langmuir isotherm constant (L/mg).

The Freundlich adsorption model is expressed as (Foo and Hameed, 2010):

$$
q_{e}=K_{F} C_{e^{\frac{1}{n}}}
$$

Where $q_{e}$ is the amount of adsorbate adsorbed at equilibrium $(\mathrm{mg} / \mathrm{g}) ; C e$ is the equilibrium metal ion concentration $(\mathrm{mg} / \mathrm{L}) K_{F}$ is the Langmuir isotherm constant $(\mathrm{mg} / \mathrm{g})$ and $n$ is the adsorption intensity.

A value of $1 / \mathrm{n}<1$ indicates better adsorption mechanism and formation of relatively stronger bond between adsorbate and adsorbent (Patil et al., 2006).

\subsection{Adsorption Kinetics}

In order to evaluate the kinetic mechanisms that control the adsorption process, experimental data were analysed using the pseudo first and pseudo second order kinetic models.

The pseudo first order kinetic model is expressed as (Sen Gupta and Bhattacharyya, 2011):

$$
\frac{d q_{t}}{d t}=k_{1}\left(q_{e}-q_{t}\right)
$$

Where $q_{e}$ and $q_{t}$ are the amount of adsorbate adsorbed at equilibrium and time $t$ respectively $(\mathrm{mg} / \mathrm{g})$ and $k_{1}$ is the pseudo first order adsorption rate constant $\left(\mathrm{min}^{-1}\right)$.

The pseudo second order kinetic model is expressed as (Ho and McKay, 1999):

$$
\frac{d q_{t}}{d t}=k_{2}\left(q_{e}-q_{t}\right)^{2}
$$

Where $q_{e}$ and $q_{t}$ are the amount of adsorbate adsorbed at equilibrium and time $t$ respectively $(\mathrm{mg} / \mathrm{g})$ and $k_{2}$ is the pseudo second order adsorption rate constant $\left(\mathrm{g} \mathrm{mg}^{-1} \mathrm{~min}^{-1}\right)$.

\subsection{Results and Discussion}

\subsection{Effect of Initial Metal Concentration}

The effect of initial metal ion concentration on the adsorption of $\mathrm{Zn}^{2+}$ and $\mathrm{Cu}^{2+}$ by yam peel biosorbent was studied as shown in Figures 1 and 2. The rate of absorption is a function of the initial concentration of metal ions, which makes it an important factor to be considered for effective biosorption. The data revealed that the adsorption capacity increased or both metal ions with increase in the initial concentration of metal ions (sorbate) as shown in Figure 1. These characteristics represent surface saturation that depends on the initial metal ion concentrations. At low concentrations, sorption sites take up the available metal ions more rapidly. However, at higher concentrations, metal ions need to diffuse to the biosorbent surface by intraparticle diffusion and greatly hydrolysed ions will diffuse at a slower rate (Horsefall and Spiff, 2005). The percent adsorption decreased slightly with increase in initial concentration due to the saturation of available sorption sites. The results are in agreement with Chen and Wang (2007). The selectivity order for metal ions towards the studied biosorbent is $\mathrm{Zn}>\mathrm{Cu}$. 


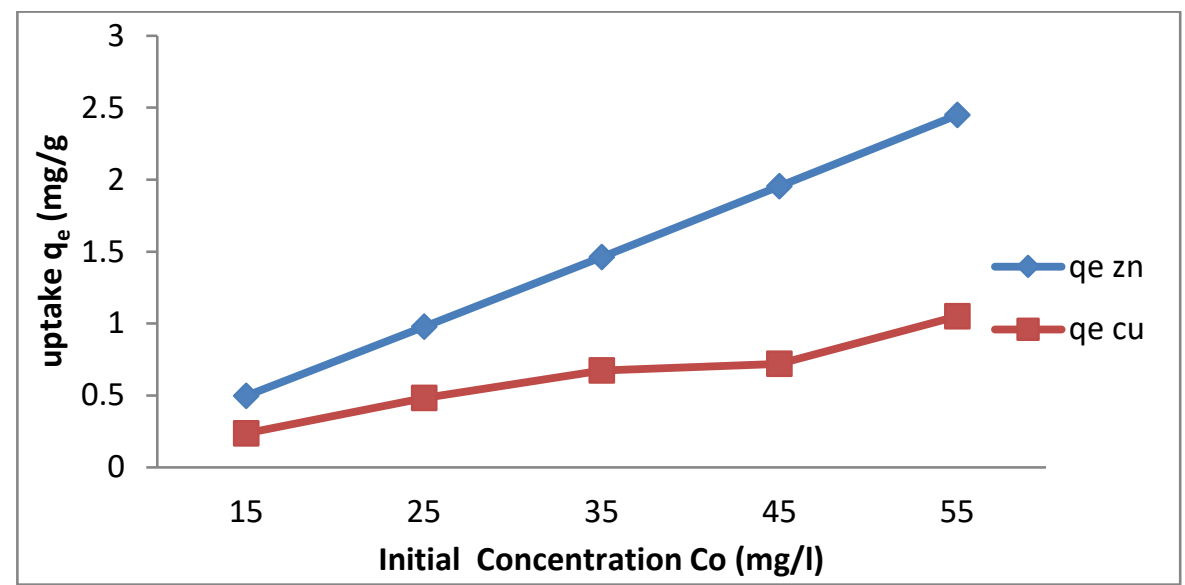

Figure 1: Effect of initial metal ion concentration on metal uptake

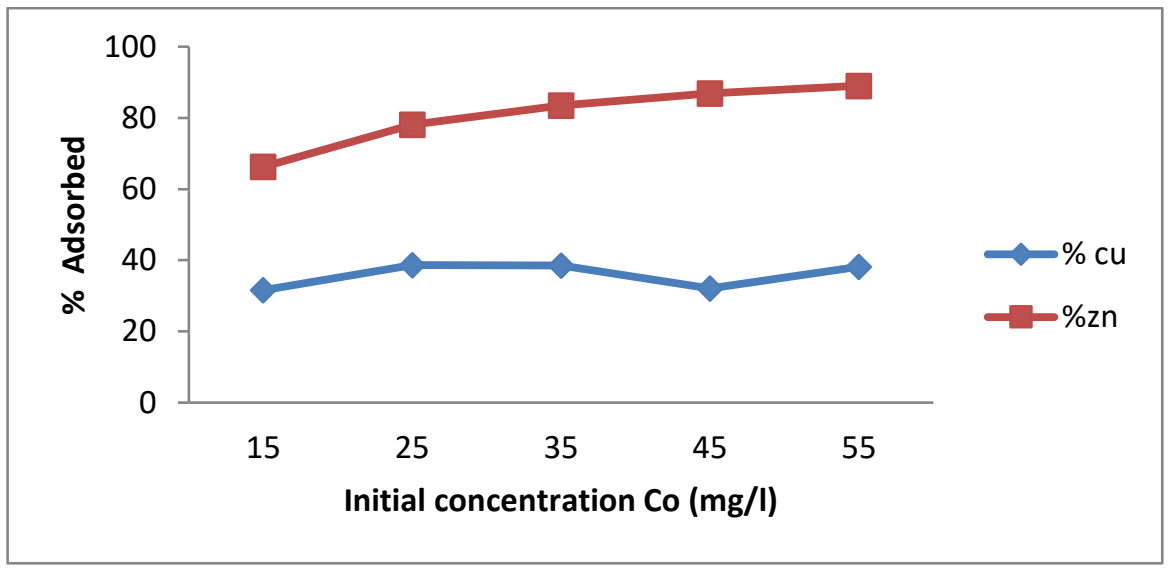

Figure 2: Effect of initial metal ion concentration on percent adsorption

\subsection{Effect of Contact Time}

The effect of contact time on the metal removal performance of the biosorbent was studied as shown in Figure 3. Contact time is an important factor, as it provides information on the minimum time required for considerable adsorption to take place and the possible diffusion controlling mechanism for the metal ion as it moves from the bulk solution towards the adsorbent surface. The adsorption of ions was rapid within the first $20 \mathrm{~min}$ after which the process proceeded very slowly. Hameed (2009) asserts that this may be due to vacant sites available at the initial stage. As the surface sites for adsorption become exhausted, the adsorption rate is controlled by the rate at which the adsorbate is transported from the exterior to the interior sites of the adsorbent, thus low rates are observed over time. The equilibrium time was reached after 20 minutes for $\mathrm{Zn}^{2+}$ and 100 minutes for $\mathrm{Cu}^{2+}$.

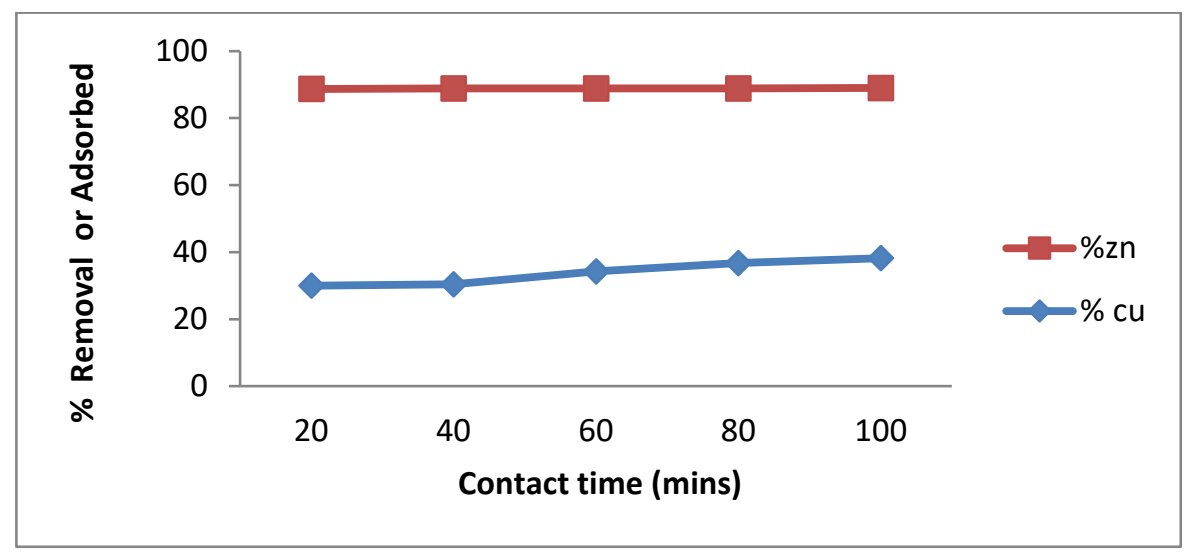

Figure 3: Effect of contact time on percent removal 
The results show that the percent removal of $\mathrm{Cu}^{2+}$ was lower (38.19\%) in comparison to the $\mathrm{Zn}^{2+}$ ions $(89.03 \%)$. This may be due to the fact that ions with smaller sizes such as $\mathrm{Cu}$ (II) ions are heavily hydrated and make the size larger and bulkier than the less hydrated (Jimoh, 2010).

\subsection{Adsorption Isotherms}

The experimental data for the uptake of $\mathrm{Zn}^{2+}$ and $\mathrm{Cu}^{2+}$ by acid-treated yam peels over the studied concentration range of $15 \mathrm{ppm}-55 \mathrm{ppm}$ were analysed using the Langmuir and Freundlich adsorption isotherm models as illustrated in Figures $4 \mathrm{a}, 4 \mathrm{~b}, 5 \mathrm{a}$ and $5 \mathrm{~b}$. The isotherm constants are summarized in Table 1.

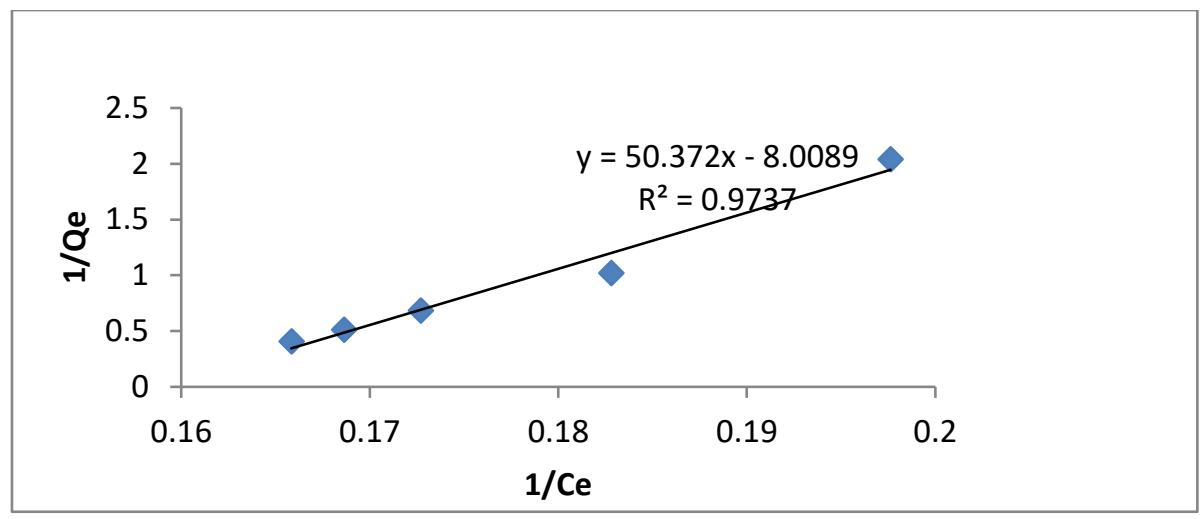

Figure 4a: Langmuir isotherm for $\mathrm{Zn}^{2+}$ removal by acid treated yam peels.

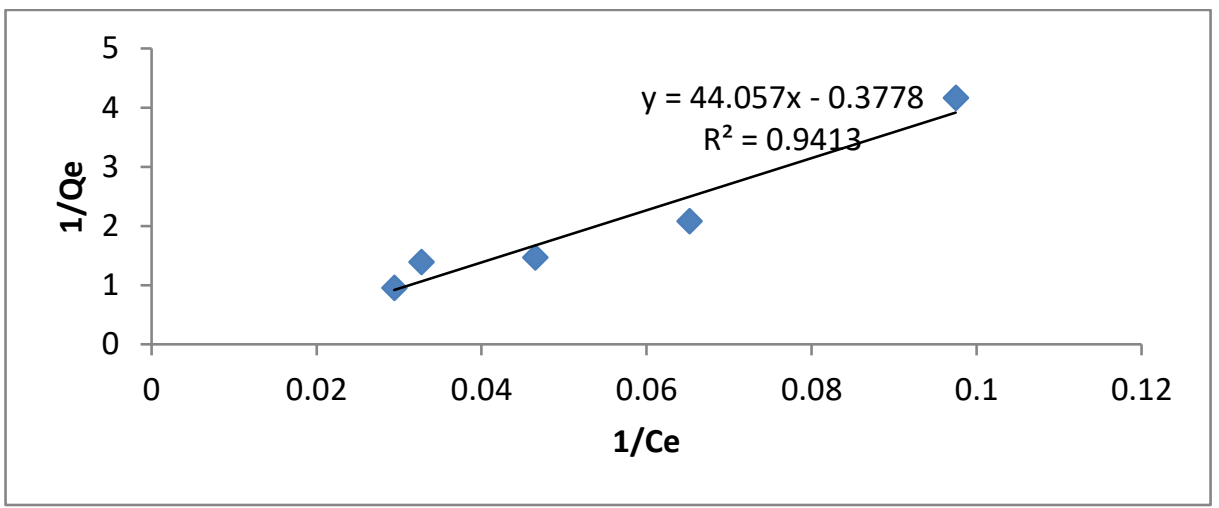

Figure 4b: Langmuir isotherm for $\mathrm{Cu}^{2+}$ removal by acid-treated yam peels.

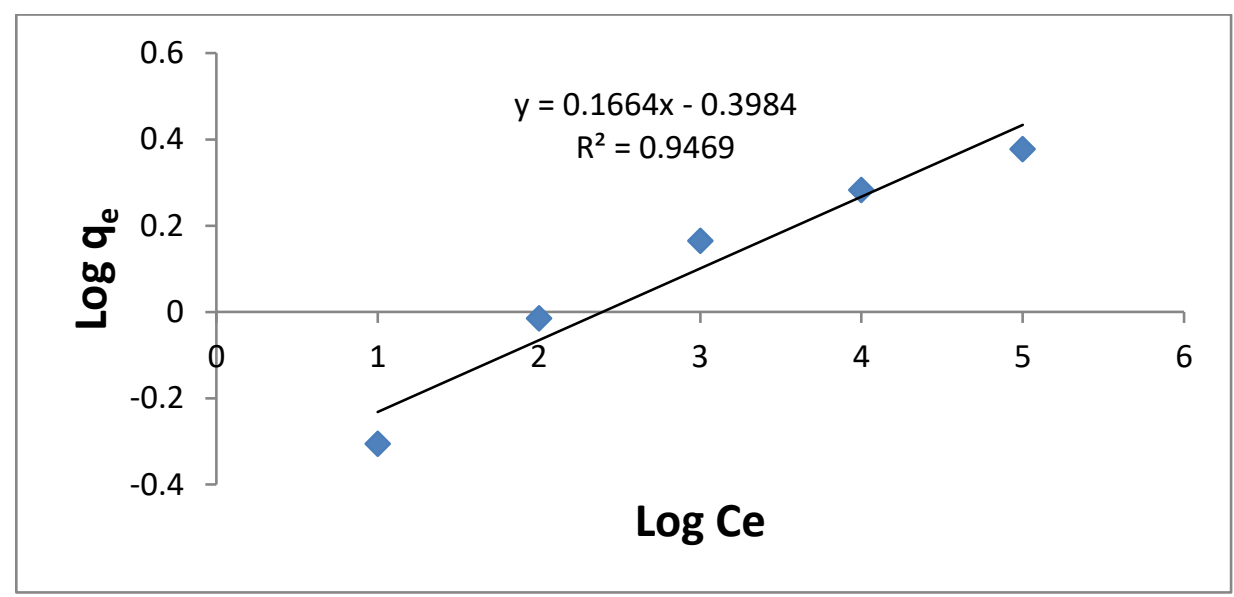

Figure 5a: Freundlich isotherm for $\mathrm{Zn}^{2+}$ removal by acid treated yam peels. 


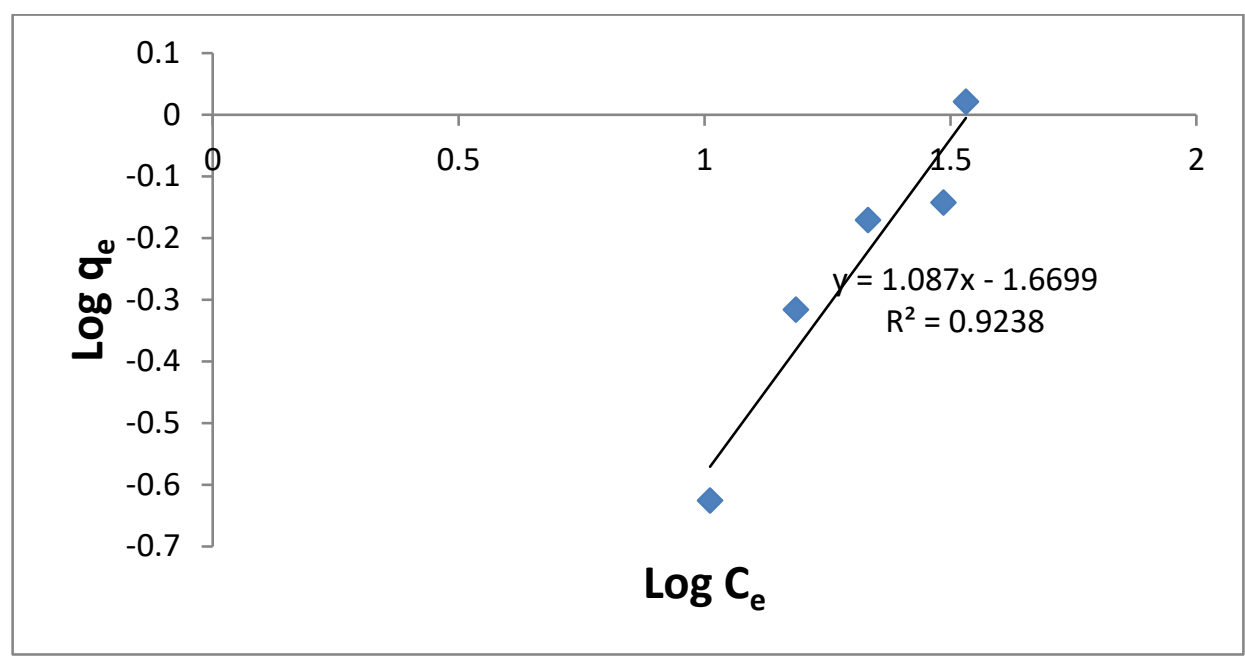

Figure 5b: Freundlich isotherm for $\mathrm{Cu}^{2+}$ removal by acid-treated yam peels.

Table 1: Langmuir and Freundlich isotherm constants for $\mathrm{Zn}^{2+}$ and $\mathrm{Cu}^{2+}$ uptake

\begin{tabular}{|c|c|c|c|c|c|c|}
\hline & Langmuir & & & Freundlich & & \\
\hline & $\mathrm{q}_{\max }(\mathrm{mg} / \mathrm{g})$ & $\mathrm{b}(\mathrm{L} / \mathrm{mg})$ & $\mathrm{R}^{2}$ & $\mathrm{~K}_{\mathrm{f}}\left(\mathrm{mg} / \mathrm{g}(\mathrm{L} / \mathrm{mg})^{1 / \mathrm{n}}\right)$ & $1 / \mathrm{n}$ & $\mathrm{R}^{2}$ \\
\hline $\mathrm{Zn}^{2+}$ & 2.50 & 0.12 & 0.974 & 1.820 & 0.166 & 0.947 \\
\hline $\mathrm{Cu}^{2+}$ & 1.10 & 0.11 & 0.941 & 0.024 & 1.087 & 0.924 \\
\hline
\end{tabular}

The Langmuir isotherm provided a better fit based on the higher values of $\mathrm{R}^{2}(0.974$ and 0.941 for $\mathrm{Zn}$ and $\mathrm{Cu}$ respectively) obtained. This indicates homogenous monolayer adsorption on a fixed number of identical sites on the biosorbent (Foo and Hameed, 2010).

\subsection{Adsorption Kinetics}

In order to investigate the adsorption mechanisms and rate of reaction, the pseudo first and pseudo second order equations were applied to model the experimental data. The Pseudo second order model (shown in Figures $6 \mathrm{a}$ and $6 \mathrm{~b}$ ) provided a better description for the uptake of both metals by the acid treated yam peels, based on the higher correlation coefficients. The kinetic constants are summarized in Table 2.

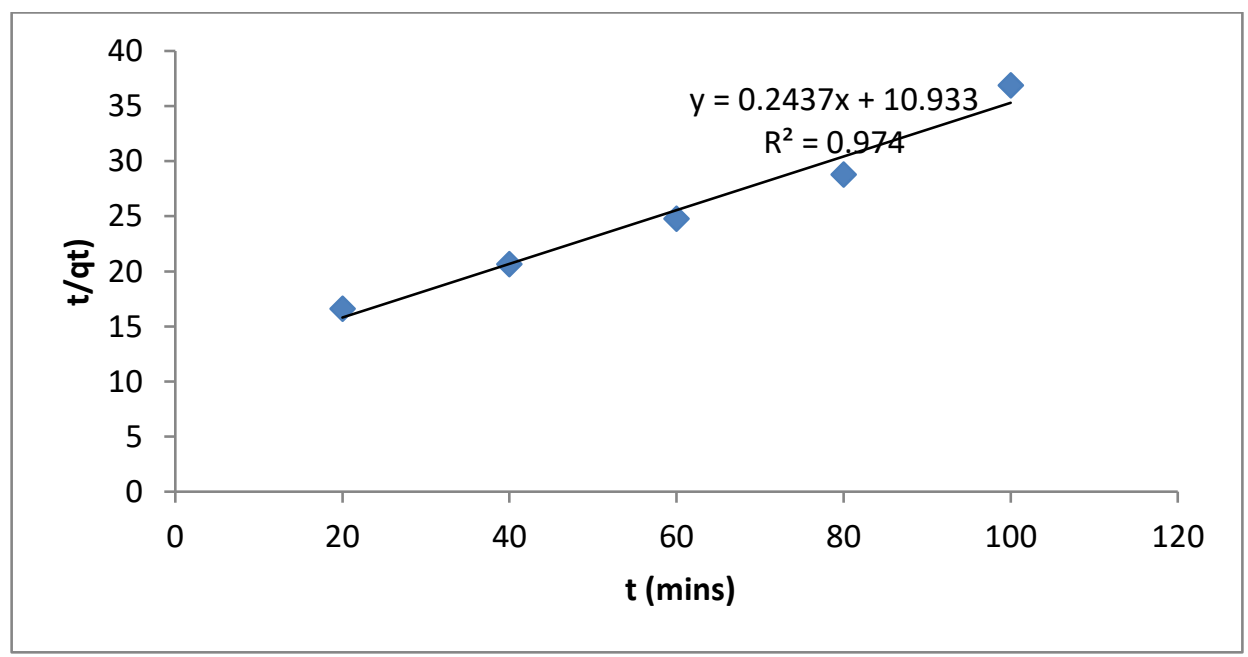

Figure 6a: Pseudo second order kinetic model plot for $\mathrm{Zn}^{2+}$ removal by acid-treated yam peels. 


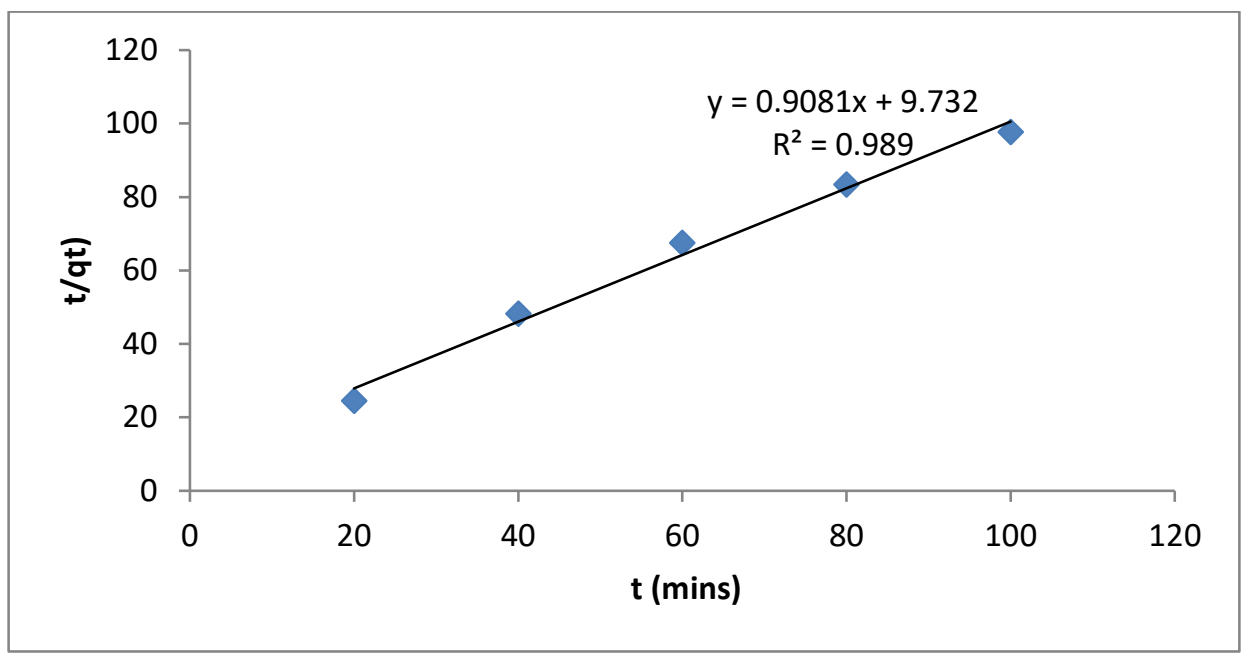

Figure 6b: Pseudo second order model plot for $\mathrm{Cu}^{2+}$ removal by acid-treated yam peels.

Table 2: Pseudo first and second order kinetic constants

\begin{tabular}{lllllll}
\hline & \multicolumn{3}{l}{ Pseudo First Order Model } & \multicolumn{4}{l}{ Pseudo Second Order Model } \\
\cline { 2 - 7 } $\mathrm{Zn}^{2+}$ & $\mathrm{q}_{\mathrm{e}, \text { calc }}(\mathrm{mg} / \mathrm{g})$ & $\mathrm{k}_{1}\left(\mathrm{~min}^{-1}\right)$ & $\mathrm{R}^{2}$ & $\mathrm{k}_{2}\left(\mathrm{gmg}^{-1} \mathrm{~min}^{-1}\right)$ & $\mathrm{q}_{\mathrm{e}, \text { calc }}(\mathrm{mg} / \mathrm{g})$ & $\mathrm{R}^{2}$ \\
\cline { 2 - 7 } $\mathrm{Cu}^{2+}$ & 1.20 & 0.012 & 0.831 & 0.104 & 1.80 & 0.974 \\
\hline
\end{tabular}

The better fit of the pseudo second order kinetic model suggests that chemisorption may be the rate limiting step, thus indicating the formation of strong covalent bonds due to the chemical interactions between the metal ions and the biosorbent surface (Ho and Mckay, 1999).

Root Mean Square Error (RMSE), Mean Absolute Deviation (MAD) and Mean Square Error (MSE) were used to measure the goodness-of-fit of the kinetic data obtained. A smaller value of these error functions indicates a better model fit and higher accuracy and validity (Tsai and Juang, 2000; Ho et al., 2005). The results are shown in Table 3.

Table 3: Statistical evaluation of adsorption kinetics for $\mathrm{Cu}$ (II) and $\mathrm{Zn}$ (II)

\begin{tabular}{|c|c|c|}
\hline Reaction orders & Metal Ions & \\
\hline & $\mathrm{Zn}$ (II) & $\mathrm{Cu}$ (II) \\
\hline $\begin{array}{l}\text { Pseudo first order } \\
\text { Root Mean Square Error (RMSE) } \\
\text { Mean Absolute Deviation (MAD) } \\
\text { Mean Square Error (MSE) } \\
\text { Coefficient of Regression }\left(\mathrm{R}^{2}\right) \\
\text { Pseudo second order } \\
\text { Root Mean Square Error (RMSE) } \\
\text { Mean Absolute Deviation (MAD) } \\
\text { Mean Square Error (MSE) } \\
\text { Coefficient of Regression }\left(\mathrm{R}^{2}\right)\end{array}$ & $\begin{array}{l}3.589234 \\
64.41302 \\
64.41302 \\
0.831 \\
\\
1.560049 \\
12.16876 \\
12.16876 \\
0.974\end{array}$ & $\begin{array}{l}6.200083 \\
192.2052 \\
192.2052 \\
0.550 \\
\\
1.20893 \\
7.30756 \\
7.30756 \\
0.989\end{array}$ \\
\hline
\end{tabular}


The pseudo second order model was found to be statistically significant for the uptake of both metal ions based on the higher values of coefficient of regression and lower values of root mean squared error (RMSE), Mean Absolute Deviation (MAD) and mean squared error (RMSE) values obtained compared to the values for the pseudo first order model. Furthermore, the linearity of the plots as depicted by higher values of $\mathrm{R}^{2}$ for the Pseudo-second order plots suggested its suitability as a model in describing the kinetic adsorption mechanism of the adsorption process.

\subsection{Conclusion}

The performance of acid-activated yam peel biosorbent for the removal of $\mathrm{Zn}$ (II) and $\mathrm{Cu}$ (II) from synthetic wastewater was explored, with findings indicating that the biosorption process was dependent on both contact time and initial metal ion concentration. The Langmuir isotherm provided a better fit for the experimental data in comparison to the Freundlich isotherm based on the higher $\mathrm{R}^{2}$ values. The pseudo second order model, as depicted by the higher $\mathrm{R}^{2}$ values, best described the adsorption kinetics. Further statistical analysis using the RMSE, MAD and MSE demonstrated the statistical significance of the pseudo second order model in comparison to the pseudo first order model due to the smaller values obtained which indicated a better model fit and higher accuracy and validity. Overall, this study has highlighted the potential of acid-activated yam peel biosorbent to be employed in the removal of $\mathrm{Zn}$ (II) and $\mathrm{Cu}$ (II) from wastewater.

\section{References}

Alderhold, D., Williams, C.J. and Edyveen, R.G.J (1996) The removal of heavy metal ions by seeds and their derivatives. Bioresource, 58: 1-6.

Aydin A, Bulut Y., Yerlikaya C. (2008) Removal of $\mathrm{Cu}$ (II) from aqueous solution by adsorption onto low-cost asorbents. Journal of Environmental Management, 87:37-45.

Badmus, M.A.O., Audu T.O.K., Anyata B.U. (2007) Removal of Lead Ion from Industrial Wastewaters by Activated Carbon Prepared from Periwinkle Shells (Typanotonus fuscatus). Turk. J. Eng. Environ. Sci. 31: 251-263.

Bailey, S.E., Olin, T. J., Bricka, R. M. and Adrian, D. D. (1999) A review of potentially low cost sorbents for heavy metals. Water Research, 33(11): 2469-79.

Blanco, A., Sanz, B., Llama, M.J., and Serra, J.L. (1999) Biosorption of heavy metals to immobilized Phormidium laminosum biomass, Journal of Biotechnology, 69: 227-240.

Chen, C., Wang, J.L. (2007) Characteristics of $\mathrm{Zn}^{2+}$ biosorption by Saccharomyces cerevisiae. Biomed Environ. Sci. 20(6): 478-482.

Foo, K.Y. and Hameed, B.H. (2010) Insights into the modeling of adsorption isotherm systems. Chemical Engineering Journal, 156(1): 2-10.

Gardea, J.L., Becker-Hapak, M.K., Hosea, J.M., and Darnall, D.W. (1990) Effect of Chemical Modification of Algae Carboxyl Groups on Metal Ion Binding. Environ Sci Technol. 24: 1372-1378.

Gardea, J.L. and Salvador, J.M. (1996) Copper Adsorption by Esterifled and Unesterified Fraction of Sphagnum peat moss and its different Humic substances. J. Hazard Mater. 48:191-206.

Hameed, B.H. (2009) Evaluation of Papaya Seed as a Non Conventional Low-Cost Adsorbent for Removal of Methylene Blue. J. Hazard Mat. 162:939-944.

Ho, Y.S., Chiu, W.T., Wang, C.C., (2005). Regression analysis for the sorption isotherms of basic dyes on sugarcane dust. Bioresour.Technol. 96:1285-1291. 
Ho, Y.S. and McKay, G.M. (1999) Pseudo second order iseppimodel for sorption process. Process Biochemistry. 34: 451-465.

Horsefall, M., Spiff, A.I. (2005) Effect of Metal ion concentration on Biosorption of $\mathrm{Pb}^{2+}$ and $\mathrm{Cd}^{2+}$ by Caladium Bicolor (Wild Cocoyam). African J. Biotechnology. 4(2): 191-196.

Igwe, J.C. and Abia A.A, (2006) A bioseparation process for removing heavy metals from wastewater using biosorbents. African Journal of Biotechnology. 5(12):1167-1179.

Jimoh, T. (2010) Pre-concentration and Removal of Heavy Metals from Aqueous Solution by African Spinach (Amaranthus hybridus L) stalk and Pawpaw (Carica papaya) seeds (Unpublished Masters thesis submitted to Postgraduate School, Federal University of Technology, Minna, Nigeria).

Mofa, A.S. (1995) Plants proving their worth in toxic metal cleanup. Science 269: 302-305.

Okuo, J.M. and Ozioka, A.C. (2001) Adsorption of lead and mercury ions on chemically treated periwinkle shells. Journal of Chemical Society of Nigeria, 26(1): 60-65.

Okuo, J.M., Pollard, G.B. and Ozioko, A.C. (2006) Adsorption of lead and mercury ions by chemically treated activated carbon almond shells. Journal of Chemical Society Nigeria, 26:60-65.

Owamah, H.I., Chukwujindu, I.S., Asiagwu, A.K. (2013) Biosorptive capacity of yam peels waste for the removal of dye from aqueous solutions. Civil and Environmental Research, 3(1):

Patil, S., Bhole, A., Natrajan, G. (2006) Scavenging of Ni(II) Metal Ions by Adsorption on PAC and Babhul Bark. Journal of Enviroment Science and Engineering, 48 (3): 203-208.

Raghavaro, J., Sivaprakash, A., Unninair, B. and Aravindhan, R. (2009) Kinetics and equilibrium studies on the biosorption of hexavalent chromium from aqueous solutions using Bacillus subtillis biomass. Journal of Applied and Environmental Research, 7(1):45- 47.

Rao, C.R.N., Iyengar, L. and Cenkobarchar (2008) Sorption of copper (II) from aqueous phase by waste biomass. Journal of Environmental Engineering division, ASCE 61: 389-377.

Sadeghi, A., Noun, J., Mohammad, M., Babaie, A.A., and Mohsenzadeh, F. (2006) Nitrite and nitrate in the municipal drinking water distribution system. International Journal of Agriculture and Biology, 8: 706-707

Sag, Y. and Kutsal, T. (1996) The Selective Biosorption of Chromium(VI) and Copper (II) ions from Binary Metal Mixtures by R. arhizus, Process Biochemistry 31: 561-572.

Sen Gupta, S. and Bhattacharyya, K.G. (2011) Kinetics of adsorption of metal ions on inorganic materials: A review, Advances in Colloid and Interface Science, 162(1-2): 39-58. istept

Tsai, S.C., Juang, K.W. (2000) Comparison of linear and non-linear forms of isotherm models for strontium sorption on a sodium bentonite. J. Radioanal. Nucl. Chem., 243:741-745. 